\title{
Correction to: Application of biochar from agro-industrial waste in solid-phase extraction for the determination of $17 \beta$-estradiol from aqueous solution
}

\author{
S. Rovani ${ }^{1,2}$ - L. F. Medeiros ${ }^{1}$ - E. C. Lima ${ }^{1}$ A. N. Fernandes ${ }^{1}$ (I)
}

Published online: 10 June 2019

(C) Islamic Azad University (IAU) 2019

\section{Correction to: \\ International Journal of Environmental Science and Technology \\ https://doi.org/10.1007/s13762-019-02295-6}

The original article was published with partial Acknowledgements. The complete Acknowledgements section is given in this correction.

Acknowledgements The authors are grateful to the Conselho Nacional de Desenvolvimento Científico e Tecnológico (CNPq, Brazil), number of financial support 140643/2012-5 (Doutorado-GD), and the Fundação de Amparo à Pesquisa do Estado do Rio Grande do Sul (FAPERGS, Brazil) for financial support and fellowships. This study was financed in part by the Coordenação de Aperfeiçoamento de Pessoal de Nível
Superior-Brasil (CAPES) - Finance Code 001. ANF thanks National Institute for Advanced Analytical Science and Technology (INCTAA, CNPq proc. 465768/2014-8) for financial support.
The original article can be found online at https://doi.org/10.1007/ s13762-019-02295-6.

\section{A. N. Fernandes}

andreia.fernandes@ufrgs.br

1 Instituto de Química, Universidade Federal do Rio Grande do Sul (UFRGS), Av. Bento Gonçalves 9500, Porto Alegre, RS CEP: 91501-970, Brazil

2 Instituto de Pesquisas Energéticas e Nucleares (IPEN-CNEN/SP), Av. Prof. Lineu Prestes, 2242, Cidade Universitária, São Paulo, SP 05508-000, Brazil 